\title{
Tratamiento informativo del Día Internacional de la Mujer en la prensa española en un contexto de crisis
}

\author{
Beatriz MARTÍNEZ RoDRÍGUEZ \\ Universidad de Vigo \\ beatrizmartinez@uvigo.es
}

Recibido: 14 de junio de 2013

Aceptado: 21 de octubre de 2013

\begin{abstract}
Resumen
Desde hace más de un siglo el 8 de marzo se conmemora en todo el mundo el Día internacional de la mujer; en las instituciones y sociedad civil aprovechan la atención de la opinión pública para mostrar sus reivindicaciones en busca de la igualdad real de derechos. En la edición de 2012 concurren en España dos circunstancias extraordinarias: la entrada del tema del aborto en la agenda política, a raíz de la propuesta de cambios en la ley introducida por el nuevo gobierno, y una situación económica crítica con reformas de profundo calado. La investigación busca analizar cómo afectan estos dos hechos a la cobertura informativa de la efeméride; hemos empleado el análisis de contenido para averiguar de qué hablan los diarios españoles cuando hablan de mujer, qué fuentes emplean y qué opiniones sustentan, y cual es su representación de la mujer en este contexto de crisis.

Palabras clave: Día internacional de la mujer; mujeres; representación de género; estereotipos; aborto

\section{News coverage of International Women`s Day in the Spanish press in a crisis context}

\begin{abstract}
For more than a century the International Women's Day is commemorated the 8th of March in the whole world; institutions and civilians take advantage of the public opinion's attention, to show their demands in order to achieve real equal rights. In 2012's edition two extraordinary circumstances come together in Spain: the entry of the abortion issue into the political agenda, as a result of the proposal of changes in the law introduced by the new government and a critical economic situation with in depth reforms. The main hypothesis aims to analyze how these 2 facts affect the information coverage of the event; we have used the content analysis to find out what the Spanish newspapers talk about when they talk about women, what kind of sources they use and what opinions they maintain and what their representation of women is in this crisis context.
\end{abstract}

Keywords: Women`s international Day; women; gender; abortion

\section{Referencia normalizada}

MARTÍNEZ RODRÍGUEZ, Beatriz (2014): “Tratamiento informativo del Día Internacional de la Mujer en la prensa española en un contexto de crisis". Estudios sobre el Mensaje Periodístico. Vol. 20, Núm. 1 (enero-junio), págs.: 451-467. Madrid, Servicio de Publicaciones de la Universidad Complutense.

Sumario: 1. Introducción. 2. Metodología. 3. Resultados; 3.1. Análisis cuantitativo; 3.1.1. Número de apariciones y extensión; 3.1.2. Secciones y página en la que aparecen las noticias; 3.1.3. Elementos periodísticos incluidos en las noticias; 3.1.4. Géneros periodísticos más frecuentes; 3.1.5. Temática y tópicos más frecuentes: 3.1.5.1. Tópicos más frecuentes; 3.1.6. Fuentes de la información; 3.1.7. Ámbito de la información; 3.2. Análisis cualitativo; 3.2.1. Debate en el Congreso sobre los cambios en la ley del aborto; reacciones; 3.2.2. Informes sobre la situación socio-laboral de las mujeres en España; 3.2.3. Actos conmemorativos y exposiciones en homenaje a las mujeres; 3.2.4. Manifestaciones y actos reivindicativos. 4. Conclusiones. 5. Referencias bibliográficas. 


\section{Introducción}

El propósito de esta investigación es analizar el tratamiento informativo que recibe la celebración del 8 de marzo, Día internacional de las mujeres, en la prensa española de 2012, a fin de determinar cuáles son los temas predominantes en la agenda de los medios con esta apelación, y cuáles las representaciones de la mujer elegidas para caracterizarla.

Las posibilidades que ofrece para ello el análisis de la cobertura informativa de un día internacional con gran raigambre -y un gran volumen de referencias en las distintas cabeceras- y la elección de medios procedentes de todo el espectro ideológico son otros argumentos que avalan el interés de la investigación.

El origen del Día internacional de la mujer-conmemorado por la ONU el 8 de marzo- se remonta a la primera década del siglo XX, y aunque no existe unanimidad sobre los desencadenantes de esta efeméride, como refiere la ONU: "hunde sus raíces en la lucha plurisecular de la mujer por participar en la sociedad en pie de igualdad con el hombre". Cualquiera que sea el origen, se ha convertido en una fecha fija en el calendario, que se conmemora con actos reivindicativos y civiles en defensa de los derechos de las mujeres y la igualdad.

Hemos analizado la cobertura mediática de esta cita en las principales cabeceras españolas -los diarios Abc, El Mundo, El País, La Razón, La Vanguardia, La Voz de Galicia y Público- recurriendo para el análisis a las hemerotecas de cada uno de los medios. Tras recabar todas las piezas referidas al tema "mujer" entre las fechas del 7 y 9 de marzo de 2012, analizamos cada contribución desde un punto de vista cualitativo y cuantitativo.

El trabajo de investigación partió de dos hipótesis principales:

- La creencia de que los temas prioritarios al hablar de mujer hoy se refieren a su situación laboral y a los criterios para medir su igualdad de condiciones real respecto al hombre, segmentada particularmente según criterios económicos, y singularmente ligado al contexto actual de crisis económica y cambios políticos y sociales en España.

- La inclusión en la agenda política, y por ende mediática, este año, de la cuestión del aborto, a consecuencia de la pregunta dirigida al ministro de Justicia, Alberto Ruiz-Gallardón, en sede parlamentaria, en la víspera de esta cita.

\section{Metodología}

El método empleado en la investigación ha sido el análisis de contenido, el más comúnmente empleado desde el comienzo de la investigación acerca de la representación informativa de la mujer.

En España se ha empleado en estudios sobre la cobertura de la violencia contra las mujeres desde los años 80 (Fagoaga, 1994); y en otros sobre la representación de la mujer: en los medios (Sánchez Aranda et al., 2003), (López Díez, 2005) y (Davara et al, 2011). También para analizar la representación de género en publicidad (Berganza y Del Hoyo, 2006), y en política (Vinuesa, Abejón y Sánchez, 2011). 
Globalmente, ha sido el método de investigación escogido en las sucesivas ediciones del ambicioso proyecto mundial GMMP ${ }^{1}$ (Ross \& Carter, 2011: 1150). En el tema concreto de la conmemoración del Día de la mujer, hay estudios previos -desde una perspectiva similar, si bien en circunstancias sociales y políticas diferentes, que hacen enriquecedora la comparación- (Gómez Patiño, 2011).

Realizamos un análisis de contenido cuantitativo y cualitativo aplicado a todas las piezas periodísticas referidas a la mujer en general, y a la conmemoración del día internacional de la mujer, en concreto, durante las fechas inmediatamente anterior y posterior al 8 de marzo en los medios de seguimiento mayoritario en España, de acuerdo a los datos de la $\mathrm{OJD}^{2}$.

El análisis ha sido cuantitativo, pues hemos obtenido datos estadísticos numéricos sobre diversos temas relevantes (número de informaciones en cada medio, extensión media de las piezas, géneros periodísticos predominantes; fuentes informativas; acompañamiento o no de imágenes...), pero hemos incorporado también métodos cualitativos para desvelar en profundidad la realidad que investigábamos: de qué hablan los medios cuando hablan del Día internacional de la mujer. Consideramos que este modo de aproximarse al objeto de estudio -partiendo de que el análisis ha de ser objetivo, sistemático y generalizador- revela con más hondura lo que queremos descubrir.

La investigación se centró en 2012 por un criterio de proximidad, y por coincidir con algunos cambios en la política nacional, que afectan a cuestiones relacionadas con la mujer -en concreto, la propuesta de introducir cambios en la vigente ley del aborto anunciada por el ministro Ruiz-Gallardón-. La búsqueda en las hemerotecas arrojó un total de 114 piezas, muestra con la que hemos trabajado. Hemos elegido los periódicos generalistas y de tirada nacional con mayor tirada y distribución, con una salvedad: $L a$ Voz de Galicia, regional, por un criterio de proximidad geográfica. Hemos seleccionado como muestra para el análisis todas las piezas periodísticas, cualquiera que sea su género, que se refieran a las mujeres o a la conmemoración de su día internacional.

\section{Resultados}

\subsection{Análisis cuantitativo}

Las categorías incluidas para el análisis de cada noticia fueron: diario, sección, fecha, número de página en la que aparece, autoría, elementos de titulación, temática más habitual, aparición de tópicos, género periodístico, extensión, fuentes de información,

1 El Global Media Monitoring Project es una iniciativa de UNIFEM se desarrolla desde 1995, coincidiendo con la Conferencia de Beijing. Consiste en analizar longitudinalmente cómo se representa a las mujeres en medios de comunicación de todo el mundo, aplicando análisis de contenido de forma simultánea a los principales diarios de hasta 43 países. Ha habido 4 ediciones (1995, 2000, 2005 y 2009-2010). Véase en http://www.whomakesthenews.org/reports/gmmp-reports.html, consultado el 18 de mayo de 2013.

2 Según la ola julio 2010/junio 2011 de la OJD, los medios más divulgados. En el periodo analizado Público, en un concurso de acreedores, dejó de editarse en papel, por lo que hemos analizado su edición digital. No lo hemos eliminado por tratarse de un medio tradicionalmente interesado en temas de mujer y políticas sociales, y con una actividad reseñable en este tema (Martínez Rodríguez, 2010: 301-319). 
ámbito e imágenes. Consideramos que estos son los elementos fundamentales a considerar para desvelar la importancia, la intencionalidad y la jerarquía establecida al tratar la cuestión, así como para hacer una primera aproximación temática al contenido, pues cada una de las decisiones adoptadas en cuanto a la titulación, la incorporación de fotografías o la consulta a unas u otras fuentes son determinantes para evaluar la consideración del tema en cada cabecera.

\subsubsection{Número de apariciones y extensión}

Porcentualmente, El País es el diario que más atención dedica, tanto en número de piezas -27- como en su extensión: una media de 618 palabras por artículo: hay varias dobles páginas. Además se refieren ya en la portada a la conmemoración y le dedican íntegra la contraportada del mismo día 8.

El diario en el que aparecen menos informaciones es Público, un medio con honda preocupación por los temas de mujer e igualdad. Achacamos esta escasa atención a la situación económica y laboral que atravesaba (en concurso de acreedores, ha prescindido de la edición en papel), y que redunda en menor disponibilidad de profesionales y medios económicos. De hecho hay solo dos piezas de opinión, al coincidir temporalmente con el cese en sus colaboraciones de muchos columnistas.

Tabla 1. Número de noticias, extensión, y número de fotografías

\begin{tabular}{|l|c|c|c|}
\hline \multicolumn{1}{|c|}{ Diarios } & Noticias & $\begin{array}{c}\mathbf{N}^{\mathbf{0}} \text { medio de } \\
\text { palabras }\end{array}$ & $\begin{array}{c}\text { Con } \\
\text { fotografía }\end{array}$ \\
\hline El País & 27 & 618 & 10 \\
\hline Abc & 23 & 363 & 8 \\
\hline La Vanguardia & 17 & 529 & 6 \\
\hline El Mundo & 16 & 543 & 6 \\
\hline La Voz de Galicia & 12 & 509 & 7 \\
\hline La Razón & 10 & 374 & 8 \\
\hline Público & 9 & 529 & 5 \\
\hline
\end{tabular}

\subsubsection{Secciones y página en la que aparecen las noticias}

Cuatro medios (El Mundo, El País, La Razón y La Vanguardia) llevan en su Portada del 8 de marzo alguna información referida a esta temática, aunque no necesariamente explicitada como Día internacional; en el caso de los tres primeros, el titular se refiere a las palabras del ministro de Justicia sobre la violencia estructural como causa del aborto; en La Vanguardia, del machismo y el imán de Terrassa. El País anuncia dos artículos de opinión de ámbito internacional.

La sección que reúne más informaciones sobre mujer en el conjunto de los diarios analizados es Opinión (33 noticias), que recoge aportaciones de diverso signo y tipología; además hay piezas que aparecen en Nacional, Contraportada o Sociedad pero pertenecen también al género argumentativo.

La segunda sección en número de artículos es la de Sociedad y Cultura (29), que reúne gran diversidad de contenidos, desde reportajes que conmemoran la efeméride a noticias de agenda con los actos programados para esta cita. Hemos incluido en esta sección algunas informaciones aparecidas bajo epígrafes más concretos o en algunos diarios que no tienen esa denominación. Es el caso de la sección "Tendencias" de $L a$ 
Vanguardia, o la llamada "Punto de mira" de La Razón, de noticias breves con un marcado carácter visual, y que abordan aspectos generalmente tratados en Sociedad.

El apartado de la interactividad está bien representado en la muestra analizada, que reproduce dos encuestas y 13 cartas de los lectores, aunque una la firma Abel Antón, parlamentario y miembro de la comisión de igualdad del congreso, por lo que estrictamente deberíamos considerarlo como una tribuna.

Las secciones regionales de los medios reproducen un gran número de noticias (23), haciéndose eco de la programación de diversas instituciones locales que conmemoran la fecha, a modo de agenda.

La celebración del Día de la mujer tiene escaso eco en las páginas de internacional; salvo la presentación de dos estudios-uno de El País, sobre cómo "Millones de bodas precoces lastran la salud y educación de las niñas", y otro de Público que reclama la atención sobre el hecho de que "Mil mujeres mueren al día en el parto o por complicaciones del embarazo"- solo hemos encontrado tres reportajes (2 en El Mundo y otro en El País); tratan de la situación de las mujeres en lugares del mundo en crisis o que viven conflictos: Afganistán, Colombia y Latinoamérica, respectivamente.

Hay un reportaje -a página completa- en la sección "Comunicación" de El Mundo, que anuncia al estreno de un programa de televisión dirigido a promover la conciliación:““¡Convive!' es un 'reality coach' donde se ayuda a parejas a buscar el equilibrio en la realización de las tareas domésticas", dice el titular.

Respecto a la localización de las informaciones, aparecen sobre todo en las páginas pares (70\%), y ocupan varias dobles y triples páginas: El País, La Voz y La Vanguardia del día 8 (en el último caso, otra el 8); en El Mundo del día 8 hay una doble página en la sección de Internacional.

\subsubsection{Elementos periodísticos incluidos en las noticias}

El 98,1\% de las piezas tienen titular y el 65,4\% lleva además otro elemento de titulación: un antetítulo (que contextualiza, como en "La Comunidad celebra el Día de la Mujer Trabajadora con actos reivindicativos que claman por la igualdad «real»" que antecede a "Mucho camino por recorrer" del $A b c$ del 9), o un subtítulo (que refiere las consecuencias o reacciones producidas por el hecho principal reflejado en el título).

Por tratarse de una efeméride señalada, varios medios cobijan las distintas piezas con esta temática común bajo un cintillo para toda la página -como las dobles o triples páginas monográficas, o de la página que $A b c$ prefigura como "En defensa de la maternidad"-, o un sumario que resalte singularmente una idea de alguna fuente (en el ejemplo de Público se reseña que "De los 867 millones de adultos analfabetos en el mundo, 550 son mujeres").

Entre los que no llevan más que el título destacan los despieces (son el 40\%) o algunos breves situados junto a la información principal de la página, y determinados tipos de géneros de opinión. Las cartas al director, los editoriales y las tribunas (en un $75 \%$ de los casos) llevan solamente un título y la referencia al cargo del autor, que justifica su firma. En las columnas analizadas, la mayoría lleva -además del título genérico de la sección: "La tronera" de Antonio Gala o "Desde la corte" de Fernando Ónega- un titular y, en un 32,6\% de los casos, también algún sumario. 


\subsubsection{Géneros periodísticos más frecuentes}

Los géneros periodísticos más empleados son los informativos (67, suponen un $58,8 \%$ de las piezas) y de opinión (42 noticias, $36,8 \%$ de las estudiadas); los ejemplos de periodismo interpretativo son exiguos $(4,4 \%)$ y se refieren principalmente a crónicas o reportajes interpretativos -los dos que El Mundo dedica a las mujeres en países en conflicto; el titulado "la futura ley del aborto, más dura", de La Vanguardia, que trata de las diferencias en las sucesivas leyes que regulan el aborto en España, y dos sobre la invisible contribución de las mujeres al arte y la cultura.

En el caso de los géneros informativos, se encontraron fundamentalmente noticias de actualidad, reportajes y entrevistas. Entre las primeras, la temática se refiere a los actos conmemorativos o reivindicativos convocados; además hay comparecencias ante la prensa de autoridades (políticos, altos cargos de la administración o representantes de sindicatos) para valorar la cuestión, y otras generadas por la interpelación al ministro de Justicia y las reacciones de los demás grupos políticos y sociales a sus palabras.

En cuanto a los reportajes, en su mayor parte son piezas intemporales, que buscan establecer el status quo de la mujer: estadísticas sobre su situación laboral o familiar, referencias a la igualdad real de derechos entre hombres y mujeres... en muchos casos reproducen datos estadísticos extraídos de informes publicados por diversas instituciones en esta fecha. Se emplea también con frecuencia el recurso a entrevistar a mujeres individuales que encarnan un rol concreto, ya sea de forma aislada, o en varias entrevistas que se incardinan en una página con una entradilla común, a modo de reportaje.

Entre las entrevistas destacan numéricamente las de mujeres que representan a un colectivo o un estereotipo (emprendedoras, mujeres que están creando empleo, madres que sostienen principalmente a sus familias), y se incluye una suerte de focus group o entrevista grupal sobre el sexismo en el lenguaje, promovido por El País con la intervención de expertos de diversos campos ("Pelea dialéctica sobre sexo y lengua", 10 de marzo).

En cuanto a las informaciones pertenecientes al género de opinión, hay ejemplos de cada una de las tipologías, si bien las más frecuentes son las columnas de opinión (13), las tribunas o colaboraciones de expertos no habituales (10) y las cartas al director (13); hay además 3 editoriales, 1 viñeta y 2 encuestas.

\subsubsection{Temática y tópicos más frecuentes}

La temática que abordan las piezas informativas es la siguiente:

a) Referida a la situación socio-laboral:

- Manifestaciones y actos reivindicativos de una igualdad real de hombres y mujeres

- Ruedas de prensa de sindicatos y partidos para hacer balance de la situación de la mujer o para anunciar acciones a desarrollar (particularmente en Andalucía, inmersa en un periodo prelectoral)

- Publicación de informes realizados por instituciones globales sobre situaciones de especial desigualdad o riesgo para las mujeres en el mundo

b) Referida a su salud y, particularmente, la reproductiva:

- Exposición sobre las fases de la vida de las mujeres y su salud 
- Debate sobre si el aborto es o no un derecho

- Debate sobre el derecho a la maternidad y la necesidad de su defensa

c) Referida a la feminidad, la igualdad o los valores que representa:

- Entregas de premios a mujeres destacadas por su labor en cualquier sector

- Actos conmemorativos, lúdicos o reivindicativos en pro de la igualdad o reconocimiento a la mujer

- Inauguración de exposiciones conmemorativas

d) Coyunturales, debido a la actualidad y los hechos noticiosos

- El debate sobre los cambios en la ley del aborto

- El apoyo del gobierno a las tesis de Gallardón

- Críticas de algunos partidos de la oposición, grupos sociales y sociedad civil

- Noticias sobre las últimas manifestaciones del imán de Terrassa, y la postura de sus fieles

- Noticia sobre la absolución por falta de pruebas de un condenado por matar a su ex pareja

- Situación de riesgo de las mujeres en determinadas situaciones coyunturales: las bodas prematuras, la mujer en condiciones de pobreza o conflicto armado...

En los reportajes se habla de hacer visible a la mujer y su contribución a la sociedad, el arte y la cultura; se amplía la mirada a la situación internacional de la mujer, prestando especial atención a los lugares o circunstancias en que sufre de mayores desigualdades.

Respecto a las entrevistas, se escogen principalmente perfiles de mujeres profesionales, que aparecen solas y hablan en primera persona de sus dificultades para conciliar, para ser tratadas en pie de igualdad en sus empresas, o de su trabajo, sin más. Se proponen en líneas generales modelos positivos, ejemplos de mujeres luchadoras y emprendedoras, o que sacan adelante sus labores. Hay también varias mujeres, ya jubiladas, a las que se trae a colación como pioneras en sus respectivos trabajos (caso de varias entrevistas en $\mathrm{La} \mathrm{Voz}$, y de mujeres homenajeadas en varios actos).

Entre las profesiones que ocupan destacan las universitarias; las paradas o con un empleo precario; las operarias del sector servicios (3 del sector textil); las que desempeñan labores artísticas (cineasta galardonada con un Óscar) y las empresarias. A pesar de que muchas de las mujeres desempeñan trabajos tradicionalmente femeninos (estudiantes de humanidades, emprendedoras de sectores como la peluquería o la estética), entre las pioneras hay mujeres procedentes del mundo científico, de las fuerzas de seguridad del estado o de profesiones tradicionalmente desarrolladas por hombres (conductoras de autobús, bomberos, etc.).

En el caso de la opinión, los temas que centran la atención son:

- El sexismo en el lenguaje: posturas a favor o en contra.

- El derecho de la mujer al aborto.

- El derecho de la mujer a la maternidad.

- El camino hacia la igualdad: estado, obstáculos, objetivos.

- La preocupación por la incidencia de la crisis económica y las medidas adoptadas por el gobierno de Mariano Rajoy en la situación de la mujer. 
- La situación global de las mujeres en el mundo (representado por las tres columnas que incorpora El País el 8, y que cita en portada: el "manifiesto por las mujeres árabes", una tribuna firmada por Michelle Bachelet y otra encabezada como "La mujer latinoamericana, la más poderosa y la más maltratada".

\subsubsection{Tópicos más frecuentes}

En la muestra analizada hay escasas reseñas del tema de la violencia, y no existen apenas referencias al género: se habla mucho de mujer o mujeres (829), y de hombres (159), mucho menos de género (31 referencias); de violencia de género (54), de violencia estructural (47), y de violencia en general (27); de aborto (169), de Gallardón (118), de vida (113), de gobierno (72), de conciliación (34) y de madres (75).

Probablemente como consecuencia de que, en principio, se denominaba a este Día de la mujer trabajadora, y a la actual situación de crisis económica y cambios en las políticas sociales, el enfoque de la mayor parte de los textos (además de al tema del aborto y la defensa de la maternidad, achacable puntualmente al debate en el congreso) se refiere a aspectos socio-laborales. Y reproduce estos tópicos comunes:

- Brecha salarial respecto al hombre.

- Mayor incidencia del paro en el colectivo femenino.

- Menos dedicación, trabajos peor cualificados, que tienen como resultado contraprestaciones sociales de menor importancia.

- Techo de cristal: tasa de puestos directivos ocupados por mujeres.

- Previsión de que la reforma laboral en curso perjudique particularmente a las mujeres (en su mayor parte, esta argumentación no está concretada en nada pues en sí no se sabe por qué va a tener consecuencias peores para la mujer, solo en un caso se cita expresamente el hecho de que, al haber menos trabajos, no van a elegir mujeres).

- Necesidad de políticas de discriminación positiva, y de apoyo a la conciliación familiar.

\subsubsection{Fuentes de la información}

Las fuentes de información de las que se nutren los diarios analizados se reparten de acuerdo al siguiente gráfico:

Tabla 2: fuentes

\begin{tabular}{|l|c|r|}
\hline \multicolumn{1}{|c|}{ Procedencia Fuentes } & $\mathbf{N}^{\mathbf{0}}$ & \multicolumn{1}{c|}{$\%$} \\
\hline Asociaciones civiles & 17 & $20 \%$ \\
\hline Institucionales o gubernamentales & 17 & $20 \%$ \\
\hline Mujeres individuales & 9 & $10,6 \%$ \\
\hline Fuentes demoscópicas/estadísticas y servicios de estudios de Universidades & 8 & $9,4 \%$ \\
\hline Mujeres con labor política & 8 & $9,4 \%$ \\
\hline Fuentes institucionales internacionales & 7 & $8,2 \%$ \\
\hline Sindicales & 7 & $8,2 \%$ \\
\hline Políticos & 6 & $7,1 \%$ \\
\hline Asociaciones privadas (Nasa, Fundación Dexeus, RTVE & 5 & $5,9 \%$ \\
\hline Judiciales & 1 & $1,2 \%$ \\
\hline
\end{tabular}


Entendemos por fuentes institucionales aquellas que representan al gobierno de un territorio, cualquiera que sea su extensión (ayuntamiento, comunidad autónoma, Estado); dado el gran número de actos convocados para celebrar la efeméride, son un recurso mayoritario.

El segundo tipo de fuentes más utilizadas responderían al concepto de la sociedad civil: convocantes de manifestaciones o interlocutores de los periodistas al hilo de la noticia generada en el pleno del congreso alrededor del tema del aborto (asociaciones provida y defensoras del aborto, feministas, etc.).

La distribución se basa, fundamentalmente, en la concurrencia de las mismas fuentes en muchas informaciones (particularmente las referidas al pleno del congreso y las reacciones), basada en información procedente de agencias, o en aprovechar las comparecencias públicas ya programadas para inquirir a gobierno y oposición sobre el tema.

Varias de las noticias sobre este hecho citan fuentes de twitter (no siempre las mismas, pero sí recurren a esta red social, y siguen a algunos personajes en común). Varias informaciones intentan dar a conocer las diferentes posturas en torno a un tema, de ahí que empleen una gran cantidad de fuentes. Sería el caso de "Gallardón dice que una "violencia estructural presiona para abortar"”, de El País del día 8, en la que concurren las asociaciones pro vida Foro Español de la Familia y Derecho a Vivir; la ACAI: asociación que agrupa a las clínicas que practican abortos; una representante de la Coordinadora de Organizaciones por la Participación y por la Igualdad...

En muchas de las informaciones de agenda que remiten a actos reivindicatorios, las asociaciones convocantes -empleadas como fuente en la noticia- son sindicales o de ayuda a la mujer (vecinales, políticas, asociativas). Y varias noticias recogen actividades privadas -exposiciones, iniciativas empresariales en pro de la igualdad, o un nuevo programa de RTVE sobre conciliación familiar-. Destaca, en el caso de $L a$ Razón, que tres de sus diez noticias abordan la inauguración de una exposición sobre salud reproductiva promovida por una fundación aneja a una clínica ginecológica privada. El foco informativo está en su inauguración por parte de las autoridades.

Entre las peculiaridades respecto a las fuentes está la cita a las comunidades islámicas en el caso de las noticias sobre el imán de Terrassa, que dicen reproducir la opinión de las mujeres del colectivo, aunque el interlocutor citado es la Unión de comunidades islámicas, no una asociación o un grupo de mujeres.

Hay reportajes que emplean como fuente principal a mujeres individuales que encarnan diferentes roles o situaciones, y que buscan representar la realidad global de la mujer; también hay casos en los que esa atención individual se ejerce sobre políticas. Pensamos que en estos casos las mujeres citadas cumplen una función de representación de mujeres profesionales con poder y visibilidad social, y se les cita por su pertenencia al sexo femenino, no por su quehacer profesional. Sería el caso de algunas menciones a Ana Botella o Dolores de Cospedal, pero no el de Ana Mato, cuyas intervenciones se reproducen en virtud de su cargo, como las del ministro de Interior; o 
de Elena Valenciano, a quien se cita como representante del PSOE, al margen de su pertenencia a uno u otro sexo.

El recurso a fuentes demoscópicas o estadísticas, así como a estudios realizados por instituciones independientes es frecuente también en las piezas estudiadas; el INE, la Fundación Adecco o la UNED son un buen ejemplo.

Las fuentes internacionales que aparecen en las informaciones consultadas se encuentran mayoritariamente en los reportajes y noticias de alcance mundial, y son en su mayoría instituciones globales, como la OMS y ONGs como Medicus mundi; o los grupos políticos del Parlamento europeo; en las noticias sobre el pleno del congreso publicadas por el diario regional ( $\mathrm{La} \mathrm{Voz} \mathrm{de} \mathrm{Galicia)} \mathrm{se} \mathrm{incluye} \mathrm{la} \mathrm{consulta} \mathrm{al} \mathrm{tercer}$ partido con mayor representación en la autonomía, el BNG, siguiendo con rigor la norma de la proximidad.

Las fuentes sindicales se emplean fundamentalmente en las noticias locales o regionales, y recogen comparecencias o notas de prensa enviadas por los responsables de igualdad en las asociaciones de trabajadores de las distintas ciudades, así como algunas entregas de premios. También destaca su presencia en algunas fotografías, al aparecer como convocantes en pancartas, por ejemplo.

Solo hay una noticia con fuente judicial, que reproduce la puesta en libertad del supuesto asesino de una mujer, por falta de pruebas, y no hemos encontrado el recurso a declaraciones policiales, pues aunque se cita con ocasión de la información sobre el imán de Terrassa que está siendo investigado, no se profundiza en esta línea de la información, y no se emplean estas fuentes.

\subsection{7. Ámbito de la información}

El ámbito territorial de interés de las informaciones es mayoritariamente nacional: 100 de las piezas circunscriben sus fuentes y su marco de referencia a España, el $89,28 \%$; en las 12 restantes el enfoque es internacional y se respeta, en general, una categorización regional.

Hay dos reportajes sobre las mujeres en Latinoamérica, que ponen el acento en las altas tasas de violencia que sufren y en la realidad de las guerrilleras en Colombia; un manifiesto de varias asociaciones de mujeres árabes, y otras piezas que alertan sobre peligros puntuales para la mujer en lugares concretos del globo, como la regresión a las políticas represoras en Afganistán...

También hay informaciones que no se adscriben a países, sino que remiten a prácticas culturales o situaciones sanitarias concretas: las que alertan de los riesgos de los matrimonios infantiles (objeto del informe "Education without borders" promovido por el ex premier británico Gordon Brown) o las que hablan de los riesgos que sufren aún hoy tantas mujeres al dar a luz (focalizado en algunos países que cita el informe de Médicos sin fronteras "Reducir la mortalidad materna en situaciones de crisis", además de la presentación en Bruselas de un Eurobarómetro sobre igualdad de género presentado que reproduce El País bajo el titular "La violencia machista y la brecha salarial, suspensos en igualdad". 


\subsection{Análisis cualitativo}

En este epígrafe se ha procedido al desglose temático de las noticias analizadas. A partir de la mayor frecuencia de aparición, hemos establecido que los temas prioritarios para los medios son:

\subsubsection{Debate en el Congreso sobre los cambios en la ley del aborto; reacciones}

El día 7 de marzo en el Congreso de los Diputados la diputada Ángeles Álvarez, del PSOE, formula por al ministro de Justicia la pregunta ¿mantiene el gobierno su intención de recortar los derechos sexuales y reproductivos de las mujeres?3.

En respuesta, como reseña El Mundo del 8 de abril, el ministro de Justicia "explicó (...) que su intención no es recortar los derechos sexuales y reproductivos de las mujeres, sino «aumentar la protección del derecho a la maternidad». Según Gallardón, «muchas mujeres ven violentado su derecho a ser madres por la presión que generan a su alrededor determinadas estructuras, que supuestos embarazos no deseados las hacen responsables únicas de esas situaciones problemáticas». En otras palabras, mantiene que a menudo, «se genera una violencia de género estructural contra la mujer por el mero hecho del embarazo» y ello se ve agravado por la falta de apoyo y de medios. $\mathrm{Y}$ en base a estos argumentos, el ministro mantiene la necesidad de legislar para «remover los obstáculos» que, en su opinión, «impiden a una mujer ser madre», ya sean de carácter familiar, laboral o social.

La ley vigente en España es la Ley Orgánica 2/2010, de 3 de marzo, de salud sexual y reproductiva y de la interrupción voluntaria del embarazo (Ley Orgánica 2010), que sustituyó a la de 1985.

La actual ley define el aborto como un derecho jurídicamente exigible, y garantiza su acceso libre (art. 12), con algunas especificaciones: será libre hasta la semana 14 de gestación (art. 14); pasado ese tiempo, y hasta la semana 22, es posible interrumpir el embarazo en caso de grave riesgo para la salud de la madre o si el feto padece anomalías graves (art. 15 a) y b). A partir de la semana 22, y hasta el término del embarazo, es posible abortar si se diagnostica al feto una malformación incompatible con la vida, o si padece una enfermedad de extrema gravedad e incurable (art. $15 \mathrm{c}$ ). Además, las menores de 16 y 17 años pueden abortar libremente, aunque es necesario el conocimiento del hecho por parte de, al menos, uno de sus representantes legales (art. 13.4).

En la ley de 1985 no se consideraba un derecho, sino que se despenalizaba como delito (tipificado en el artículo 147 de Código penal) en tres supuestos: si el embarazo suponía un grave peligro para la salud o la vida de la mujer, si era probable que el feto naciera con graves taras físicas o psíquicas, o si el embarazo era fruto de una violación.

${ }^{3}$ La interpelación lleva el número de expediente 180/000059; consúltese la literalidad de las intervenciones en el diario de sesiones del congreso, accesible en http://www.congreso.es/public_oficiales/L10/CONG/DS/PL/PL_016.PDF 
La atención prestada por los diarios a las palabras del ministro Gallardón y a la realidad del aborto es bastante similar -en términos cuantitativos- en los medios analizados; todos se hacen eco en varias ocasiones del tema, y le dedican en su mayor parte el editorial o columnas de opinión en lugares preminentes y con autores que el lector identifica claramente con su línea editorial.

Los que prestan más atención a esta temática son El Mundo y Público, con 6 piezas. El primero tiene 2 informativas y 4 de opinión, y Público dedica 2 columnas y 4 noticias al tema: presenta el debate, refiere el apoyo del gobierno a la tesis, reproduce las críticas vertidas por el principal grupo de la oposición, y muestra una manifestación en la que se pide la dimisión del político.

Todos los medios se hacen eco del debate, y la mayoría subraya que no se trata de una opinión aislada del ministro de Justicia, sino que está arropado por sus compañeros de gobierno y/o partido. Mientras, en $A b c$ dedican una noticia a tratar de contrastar la información reseñada por Gallardón (reproducen la opinión y experiencias de una red asistencial solidaria de ayuda a mujeres embarazadas en dificultades, Red Madre, al respecto de la presión que sufren las embarazadas), y en La Vanguardia hacen una análisis de las dos leyes anteriores del aborto aprobadas en España, y una labor de interpretación de cuáles pueden ser los cambios introducidos por el PP en la próxima reforma.

Los argumentos y contenido general de las informaciones, más allá de algunas variaciones motivadas por el recurso a diferentes fuentes, son comunes: se incorporan las declaraciones del ministro y la diputada interpeladora, de alguna asociación contraria al aborto, de la agrupación de clínicas que practican abortos, de asociaciones feministas, sindicales o políticas, etc. Casi todos los medios reproducen las palabras al respecto de los mismos personajes: los ministros Mato y Fernández Díaz, Esperanza Aguirre, Elena Valenciano...

Las noticias contienen en muchos casos elementos opinativos, ya en el propio titular ("La izquierda se levanta contra Gallardón"; "Gallardón irrita a la izquierda al atribuir los abortos a la falta de medios para tener hijos" o "Gallardón incendia el Congreso con su teoría sobre el aborto") por el contrario, en $\mathrm{La}$ Voz titulan "El Gobierno respalda a Gallardón sobre el aborto, mientras arrecian las críticas".

Las informaciones sobre el debate no reproducen la pregunta al ministro, y sí su respuesta; algunas las acompañan ya con las reacciones en la misma noticia (diferentes opiniones en twitter o de otros grupos políticos, postura de otros miembros del gobierno o de la ejecutiva del PP apoyando la tesis de Ruiz-Gallardón...). En estas piezas no hay argumentación más allá de las propias palabras del ministro, y el intento de comprensión de su propuesta.

En cuanto a las piezas de opinión que tratan el tema, son casi tan numerosas como las propias noticias, como veíamos en el cuadro: hay 13 columnas y artículos, y 2 editoriales, y en ellas se perciben las diferentes posturas de los medios al respecto del aborto.

Los editoriales corresponden al $\mathrm{Abc}$ y El Mundo. El primero, bajo el título "Feministas a tiempo parcial" critica "que el movimiento feminista (jaleado por PSOE e IU) se manifestase airadamente contra el ministro de Justicia por romper una lanza en 
favor de la maternidad y en contra del aborto, pero no dijese nada para criticar al imán de Tarrasa que incitaba a maltratar a las mujeres". El editorial de El Mundo "Gallardón escribe recto con renglones torcidos" lamenta el uso de una terminología que consideran incomprensible, si bien apoyan su tesis de fondo y le felicitan por "plantear el debate -controvertido en términos legales y morales- desde una nueva perspectiva".

En cuanto a las columnas, cada una de ellas responde a la opinión de su autor, y cubren todo el espectro, desde la defensa encendida de la propuesta del ministro por parte de Isabel San Sebastián, hasta la descalificación (expresada de modo un tanto incomprensible) de Antonio Gala.

Entre las que se muestran a favor de la postura del ministro los textos son más argumentativos, y van al fondo de la cuestión planteada; entre los detractores abunda la descalificación personal, o la atribución de las palabras del ministro a un mero afán protagonista, con la excepción de Fernando Ónega, que intenta profundizar en la cuestión, y reclama datos que justifiquen el cambio de ley. Otros, como Maruja Torres, consideran las palabras de Gallardón tan solo una vuelta de tuerca a los argumentos en torno al aborto, y un intento de cambiar la sociedad precedido por los cambios en el lenguaje (en línea con los argumentos de la reciente polémica acerca del sexismo en el lenguaje).

\subsubsection{Informes sobre la situación socio-laboral de las mujeres en España}

El segundo tema más tratado en las noticias analizadas busca hacer un diagnóstico de la realidad de la mujer en España, deteniéndose principalmente en los aspectos laborales y de igualdad de responsabilidades, derechos y potencialidades respecto al hombre.

Para orientar la opinión de los lectores se incluyen en las noticias datos estadísticos procedentes del INE en varios casos; otros los firman agrupaciones sindicales o servicios de estudios universitarios o de ONGs.

Los datos principales que se abordan en estos casos son, a grandes rasgos, comunes:

- cifras absolutas y relativas de tasa de ocupación

- diferencia salarial entre hombres y mujeres

- porcentaje de puestos directivos ocupados por mujeres

- tipo de contrato y ocupación de hombres y mujeres

- corresponsabilidad y conciliación familiar y cuidado de dependientes...

En general, las informaciones que emplean este argumento señalan la difícil situación económica y social que se vive en España, y particularmente las mujeres; cómo los parámetros que nos permiten juzgar la situación no demuestran una igualdad real de oportunidades a hombres y mujeres, y en el miedo -reproducido en varias cartas de lectores- a que la situación relativa de las mujeres empeore a consecuencia de las medidas adoptadas para salir de la crisis, o de reformas como la laboral. Estas informaciones aportan abundante información estadística, pero no concretan cómo afectará a la población femenina el nuevo escenario: se advierte del peligro pero no se plasma con ejemplos, no se cita ningún aspecto concreto de la ley. 
Se piden en varios casos una discriminación positiva a favor de la mujer, y medidas de conciliación de la vida laboral y familiar, y acceso a la formación, como cauce para mejorar su situación real.

Por medios, La Voz de Galicia dedica porcentualmente la mayor parte de su interés a la situación laboral; hay una página completa dedicada a aportar información estadística, aderezada con gráficos informativos; se dedica una noticia a reseñar que "La mitad de los cuidadores no profesionales que avalaron su experiencia están trabajando", y de ellos, un $86 \%$ son mujeres, y otra página completa reúne 4 entrevistas a mujeres en situación precaria, que transmiten su experiencia.

También $A b c$ dedica mucho espacio -7 noticias- a reflejar las reivindicaciones laborales expresadas en las distintas comparecencias de los responsables de igualdad de los sindicatos, que hacen hincapié, como se reseña en una de sus noticias, en que el de hoy "no es un Día de la Mujer «al uso» sino está marcado por el «agravamiento» de las condiciones de vida de la población, en general, y de las mujeres en particular. «La igualdad real no está ni mucho menos conseguida y estamos en un serio riesgo de retroceso por las políticas del Gobierno y la reforma laboral»".

En El País hay varios artículos de opinión con esta temática. Dos son cartas de lectores que temen por el empeoramiento de la situación económica y su influencia sobre las mujeres, ya peor posicionadas, y otra una tribuna de opinión de la consejera andaluza de Igualdad en la que repasa todos los tópicos relacionados con la mujer (el género, la salud reproductiva, la situación laboral, su papel en la familia y en la sociedad...) y alerta de posibles retrocesos en la igualdad a resultas del cambio de gobierno y los recortes provocados por la crisis.

Para ilustrar esta temática se recurre en varios medios a incluir entrevistas a mujeres que hablan de su situación laboral. En general, el tono de estos textos es positivo y laudatorio; presenta modelos femeninos atractivos y contundentes (es el caso de la entrevista a una cineasta paquistaní que acaba de ganar un óscar por un documental sobre los ataques con ácido a mujeres en su país, o del despiece "Las mujeres amortiguan la caída en el colectivo de los autónomos" del $A b c$ de Castilla y León del mismo día.

\subsubsection{Actos conmemorativos y exposiciones en homenaje a las mujeres}

Las informaciones sobre los actos lúdicos, y los homenajes celebrados en este día son numerosas, especialmente en los medios que comparten línea editorial con los dirigentes de las instituciones que los convocan; en su mayor parte, reproducen actos institucionales convocados por gobiernos locales o regionales para homenajear a determinadas mujeres que representan un rol o un valor determinado.

En el caso del reportaje de $A b c$ "Homenaje a las mujeres que afrontan su día a día «con fuerza, valentía y esfuerzo»", se incluye una foto de las premiadas junto a Esperanza Aguirre, promotora del acto, y se enuncia por qué se concede el galardón: su capacidad de liderazgo, entrega y superación, talento, esfuerzo y trabajo solidario... valores tanto humanos como profesionales. Estos son también los roles que representan: una artista, la primera bombero, una empresaria, dos mujeres que dirigen asociaciones solidarias... La misma idea se cumple en otros reportajes de $A b c$, y $L a V o z$, que informan del reconocimiento a varias pioneras por su labor en diversos campos. 
Tanto Abc como El Mundo se hacen eco de las propuestas de los políticos responsables de Igualdad (como en el artículo "Hacia la igualdad de las mujeres" que firma el Secretario de Estado de Servicios Sociales e Igualdad, por ejemplo, toda una declaración de intenciones programática sobre sus objetivos para los próximos años, o en la columna de El País "Ni un paso atrás", de su homóloga andaluza, previniendo de posibles recortes en derechos a las mujeres si se produce el cambio en el gobierno de su Comunidad.

No existe esta temática en ningún texto de El País, La Vanguardia o Público, y sólo en uno en el caso de El Mundo.

\subsubsection{Manifestaciones $y$ actos reivindicativos}

En general, las informaciones que emplean este argumento hacen hincapié en el tiempo y esfuerzo invertidos por las mujeres en avanzar en igualdad respecto a los hombres, y se pone el acento en el miedo a retroceder en derechos y condiciones de vida, supeditadas a la situación económica y a los cambios iniciados por el nuevo gobierno del Partido popular.

Este tipo de noticias reproduce manifestaciones y actos para reclamar avances en igualdad o protestar por determinadas políticas locales, o nacionales. Son menores en número, su extensión no es tan importante como en los reportajes sobre homenajes o sobre coyuntura laboral, y todas reproducen imágenes de activistas manifestándose, con pancartas en las que se pueden leer sus principales requerimientos y los nombres de los convocantes. En su mayor parte remiten a actos en España, aunque hay algún ejemplo - de La Vanguardia, sin ir más lejos- que repasa visual y textualmente las principales manifestaciones al respecto en todo el mundo, dejando patente que se trata de una conmemoración global.

Por medios, prestan más atención a estos argumentos el $A b c$ (3 noticias) y La Vanguardia (que incide en que, con la crisis, cada vez son más las mujeres que aportan el suelo principal a la economía familiar, pese a tener trabajos peor valorados y remunerados). La Razón no utiliza este tema en ninguna información.

Un caso que merece atención es el de varias piezas informativas, localizadas en Andalucía, que anuncian medidas futuras (o publicitan medidas ya adoptadas) de promoción de la mujer, propuestas por diferentes partidos políticos en distintos medios. Este foco de interés coincide temporalmente con el periodo prelectoral en esta comunidad.

Otros temas objeto de atención preferente en los casos estudiados son la necesidad de hacer visible la contribución de las mujeres al arte; el debate sobre las cuotas como modo de asegurar la presencia de la mujer en distintas facetas de la sociedad; la reflexión sobre cómo garantizar el derecho a la maternidad y las políticas de conciliación o las noticias sobre las declaraciones del imán de Terrassa sobre la mujer y las reacciones de sus fieles.

\section{Conclusiones}

Las principales conclusiones que hemos extraído del estudio realizado son:

1. El interés por abordar la temática de la mujer, especialmente con motivo de una efeméride, es patente en los medios nacionales analizados, que tratan abundantemente 
la cuestión, le conceden una extensión singular, y lo citan en la portada o en lugar preferente.

2. En la agenda informativa de esta edición destacan -por número y espacio destinado- las piezas referidas al debate en torno a los posibles cambios en la ley del aborto. Este argumento informativo es también objeto de muchos textos de opinión.

3. El foco informativo en las piezas de opinión gira en torno al posible empeoramiento de la situación de la mujer en el actual contexto de crisis y de cambio político, ya sea por la situación socio-laboral o por los potenciales cambios legislativos introducidos por el gobierno actual.

4. La categorización de la mujer se refiere, mayoritariamente, a sus circunstancias laborales, y a su situación relativa en comparación con el hombre; las mujeres a las que se entrevista o homenajea en los casos analizados lo son casi siempre por su trayectoria profesional.

5. La atención principal de los medios españoles se circunscribe a la situación de las mujeres en España y en el escenario presente, con sus peculiares características, y en un escenario de cambio. En las informaciones internacionales, remiten a lugares conflictivos donde no se respetan los derechos de la mujer o a estudios internacionales que profundizan en dificultades concretas de colectivos femeninos.

6. El tipo de efeméride y el contexto político (con un gobierno en sus primeros 100 días de mandato, y un periodo prelectoral en dos comunidades autónomas) explica que se incluyan varias tribunas de opinión a cargo de políticos o representantes institucionales para hacer una valoración sobre el estado de la cuestión, o no previsible devenir.

7. Los ejemplos concretos de mujer que se ofrecen para ilustrar reportajes y estadísticas son, en general, positivos, y patentizan el valor de las mujeres y la lucha por lograr sus metas pese a las dificultades.

8. Las fuentes informativas que consultan preferentemente los medios para informar de acontecimientos como éste son institucionales y políticas, sujetas a la agenda política y sindical y a las manifestaciones de agrupaciones civiles y de mujeres.

9. Los argumentos sobre la violencia, las relaciones familiares o sociales y el ámbito humano de la mujer no suscitan el interés de la prensa en esta conmemoración del Día internacional de la mujer.

Comprobamos, por tanto, la veracidad de las dos hipótesis iniciales de esta investigación: la atención preferente de los periódicos españoles en la celebración del Día internacional de la mujer de 2012 se ciñe informativamente al debate en torno a las causas del aborto esgrimidas por el ministro de Justicia, y a los posibles cambios en la ley que lo regula, y la caracterización de la mujer se basa principalmente en su faceta laboral, marcada por el miedo al retroceso en materia de igualdad de derechos con el hombre en un contexto de crisis económica y cambio político.

\section{Referencias bibliográficas}

BERGANZA CONDE, Rosa, y DEL HOYO HURTADO, Mercedes (2006): "La mujer y el hombre en la publicidad televisiva: imágenes y estereotipos". Zer, vol. 21, pp. 161-175. Leioa, Universidad del País Vasco. 
DAVARA, Javier et al (2010): "Presencia e imagen de la mujer en la prensa española". Cuadernos de Periodistas, $\mathrm{n}^{\circ}$ 21, pp. 107-119. Madrid

FAGOAGA, Concha (1994): "Comunicando violencia contra las mujeres". Estudios sobre el Mensaje Periodístico, vol. 1, pp. 67-90. Madrid, Servicio de Publicaciones de la Universidad Complutense.

GÓMEZ PATIÑO, María (2011): "Análisis del tratamiento de la mujer en la prensa española. Día Internacional de las Mujeres". Estudios sobre el Mensaje Periodístico, vol. 17, $\mathrm{n}^{\mathrm{o}} 1$ (enero-junio), pp. 119-140. Madrid, Servicio de Publicaciones de la Universidad Complutense.

LÓPEZ DÍEZ, Pilar (2005): $2^{\circ}$ Informe Representación de género en los informativos de radio y televisión. Madrid, Instituto Oficial de Radio y Televisión (RTVE) e Instituto de la Mujer.

Ley Orgánica 9/1985, de 5 de julio, de reforma del artículo 417 bis del Código Penal, publicada en BOE $n^{\circ}$. 166, del 12 de julio de 1984, p. 22041: http://www.boe.es /aeboe/consultas/bases_datos/doc.php?id=BOE-A-1985-14138 [fecha de consulta: 26 de mayo de 2013].

Ley Orgánica 2/2010, de 3 de marzo, de salud sexual y reproductiva y de la interrupción voluntaria del embarazo, publicada en $\mathrm{BOE}^{\circ}$. 55, del 4 de marzo de 2010, pp. 21001 a 21014: http://www.boe.es/boe/dias/2010/03/04/pdfs/BOE-A-20103514.pdf [fecha de consulta: 26 de mayo de 2013].

MARTÍNEZ RODRÍGUEZ, Beatriz (2010): "La respuesta de la audiencia al compromiso adquirido por el diario Público con su «Decálogo para informar sobre violencia de género»", en VV.AA: Las audiencias activas, nuevas formas de participación pública (Coord., Vicente VIDALCLIMENT). Guadalajara, México, Fundación Coso y Universidad Panamericana.

ROSS, Karen y CARTER, Cyntia (2011): "Women and news: A long and winding road". Media, Culture \& Society vol. 33, 8, pp. 1148-1165.

SÁNCHEZ ARANDA, José Javier, BERGANZA CONDE, Rosa y GARCÍA ORTEGA, Concha (2003): Mujer publicada mujer maltratada: libro de estilo para informar en los medios de comunicación sobre la mujer. Pamplona, Gobierno de Navarra.

VINUESA TEJERO, María Lourdes; ABEJÓN MENDOZA, Paloma; y SÁNCHEZ CALERO, María Luisa (2011): "Mujeres y política: un binomio con baja representación". Ámbitos 20, pp. 127-145, Sevilla, Universidad de Sevilla. 